\title{
Arztkontakt nur noch über das Internet?
}

\author{
Schon 500 deutsche Patienten und es werden mehr: Das Internetportal \\ "DrEd.com" sorgt für Furore. Während Ärzteverbände hierzulande auf die \\ Barrikaden gehen, lässt die Briten der Trubel kalt. Der Betreiber bleibt gelassen \\ - und plant bereits die Expansion.
}

— Völlig unbeachtet von der britischen Öffentlichkeit ist Anfang der Woche der deutschsprachige Teil der Internet-Praxis DrEd (www.dred.com) online gegangen. Deutsche Ärzte behandeln dabei von London aus via Internet Patienten in Deutschland als Selbstzahler und stellen ihnen auch Rezepte aus.

"Solche Internetportale sind hier in England nichts Neues", so ein Sprecher des britischen Ärztebundes (British Medical Association, BMA).

Das aus deutscher Sicht kontrovers beurteilte Internetportal beschäftigt laut eigenen Angaben derzeit zwei ausgebildete Ärzte, einen Urologen und einen Allgemeinmediziner. Das Unternehmen operiert laut Sprecher Jens Apermann „aus rechtlichen Gründen“ von Großbritannien aus. In Großbritannien sei das Angebot legal, in Deutschland je-

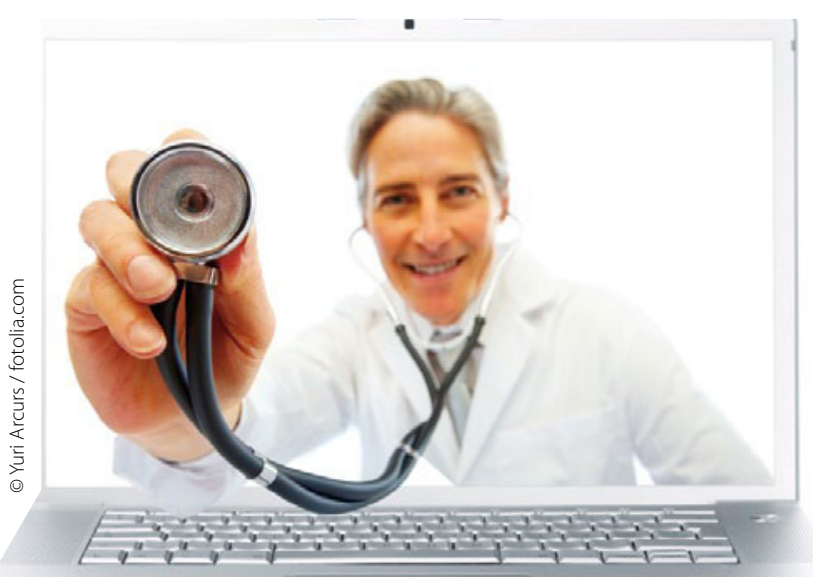

$\bullet$

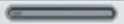

Wenn das der einzige Weg zum Arzt ist ... doch stehe die Berufsordnung dagegen. „Die Telemedizin ist in Großbritannien seit längerem etabliert und erfolgreich", so Apermann weiter. „Außerdem sind die bei uns arbeitenden Ärzte in London ansässig."

Während das Internetportal seit der Einrichtung eines deutschsprachigen Dienstes hierzulande für Debatten sorgt, kannte man beim britischen Ärztebund BMA nicht einmal den Namen des Unternehmens.

\section{Das Rezept kommt mit der Post}

Laut Apermann koste eine Konsultation bei "DrEd.com“ je nach Aufwand zwischen neun und 29 Euro. Patienten mit Asthma, Bluthochdruck, Blasenentzündungen und anderen Krankheiten können sich bei dem Portal per Mausklick „behandeln“ lassen.

Die Patienten bekommen ihr Rezept per Post, oder die Medikamente werden durch eine Online-Apotheke zugesandt. Ein persönliches Telefonat mit einem Arzt sei möglich. Die Praxisgebühr entfalle.

Ungeachtet der Kritik aus Deutschland will das Unternehmen, das seinen englischsprachigen Dienst bereits seit August 2011 betreibt, weiter expandieren. „Wir haben entsprechende

Vorstellungsgespräche mit deutschsprachigen Ärzten geführt", hieß es.

In den nächsten Wochen würden zusätzliche
Mediziner eingestellt. Derzeit müssten sich Patienten je nach dem Zeitpunkt ihrer Anfrage auf Wartezeiten von „maximal drei Stunden“ einstellen. „In Ausnahmefällen" könne der Patient erst am nächsten Werktag mit ärztlicher Hilfe rechnen.

Derzeit seien 500 Patienten eingeloggt um therapiert zu werden, erläuterte Apermann. Das Angebot sei auch bei Patienten beliebt, die „aus Schamgefühl den persönlichen Kontakt mit einem Mediziner vermeiden wollen“.

\section{"Wir sind kein Arzt-Roboter"}

Unterdessen warnen Ärzteverbände in Deutschland vor dem Internetportal. „Es kann einen Arztbesuch nicht ersetzen“, so der Sprecher der Kassenärztlichen Bundesvereinigung (KBV), Roland Stahl. Diagnose und Behandlung allein über das Internet könne nicht im Interesse des Patienten sein.

Andere Verbandssprecher wiesen darauf hin, dass laut deutschem Recht Patienten nicht ausschließlich über Printund Kommunikationsmedien behandelt oder beraten werden dürften.

Genau darin sieht „Dr.Ed.com" offenbar seine Marktchance. „Das Internet ist eine Realität, und wir sind der Meinung, dass 2011 die Zeit reif ist für unser Angebot", so Apermann.

„Wir sind kein Arzt-Roboter, aber wir nutzen die neue Technologie, um Ärzte und Patienten zusammen zu bringen."

Die negative Reaktion seitens der deutschen Ärzteschaft überrasche ihn nicht. „Damit haben wir schon gerechnet." Allerdings gebe es vor allem unter jüngeren Ärzten in Deutschland „durchaus auch positive Reaktionen“.

AST 